Research Article

\title{
Catalytic Activity of Ni, Co, Mo Supported Anodic Aluminum Oxide Nanocomposites
}

\author{
Anvar Xamidov ${ }^{1}$, Farhodjon Hoshimov', Shavkat Mamatkulov², Khakimjan Butanov', \\ Mirakhmat Yunusov ${ }^{3}$, Olim Ruzimuradov ${ }^{1,4, *}$ \\ ${ }^{1}$ Department of Chemistry, National University of Uzbekistan, Vuzgorodok 15, Tashkent 100174, \\ Uzbekistan. \\ 2Institute of Material Science, Academy of Sciences of the Republic of Uzbekistan, Chingiz Aytmatov 2b, \\ Tashkent 100084, Uzbekistan. \\ ${ }^{3}$ Uzbek Research Chemical and Pharmaceutical Institute, Durmon Yuli 40, Tashkent 100125, \\ Uzbekistan. \\ ${ }^{4}$ Department of Natural and Mathematic Sciences, Turin Polytechnic University in Tashkent, Kichik \\ khalqa yoli 17, Tashkent 100095, Uzbekistan.
}

Received: $4^{\text {th }}$ September 2020; Revised: $6^{\text {th }}$ November 2020; Accepted: $9^{\text {th }}$ November 2020;

Available online: $10^{\text {th }}$ November 2020; Published regularly: December 2020

\section{Abstract}

Nanostructured catalysts based on porous aluminum oxide (PAO) and some 3d metals, such as: nickel, cobalt, and molybdenum, have been obtained by anodic oxidation and impregnation. The synthesis of porous aluminum oxide with a highly ordered pore structure with pore sizes of $50 \mathrm{~nm}$ and a thickness of $50 \mu \mathrm{m}$ is carried out by the method of two-stage anodic oxidation. The catalysts are obtained by impregnation of $3 \mathrm{~d}$ metals into nanosized pores of aluminum oxide. The obtained catalysts based on nickel and porous $\mathrm{Al}_{2} \mathrm{O}_{3}$ are studied by scanning electron microscopy (SEM-EDX). The results of SEM-EDX analysis shows that a spongy structure with filament sizes of 100 nanometers containing particles of $3 \mathrm{~d}$ metals formed on the surface of the aluminum oxide matrix. The results are presented on the activity of nickel and heterogenic cobalt and molybdenum nanoparticles in the reaction of hydrogenation of hexene to hexane. The results show that the yield temperature of the hexane is decreased and the yield of hexane is observed at $200{ }^{\circ} \mathrm{C}$ with $\mathrm{Ni} / \mathrm{Al}_{2} \mathrm{O}_{3}$ catalysts, and a similar yield of hexane mass is achieved at temperatures higher than $250{ }^{\circ} \mathrm{C}$ with $\mathrm{Co}-\mathrm{Mo} / \mathrm{Al}_{2} \mathrm{O}_{3}$ and traditional nickel catalysts on kieselguhr. Copyright (C) 2020 BCREC Group. All rights reserved

Keywords: Anodic aluminum oxide; Controllable electrochemical anodization; nickel nanoparticles; hydrogenation; olefin

How to Cite: Xamidov, A., Hoshimov, F., Mamatkulov, S., Butanov, K., Yunusov, M., Ruzimuradov, O. (2020). Catalytic Activity of Ni, Co, Mo Supported Anodic Aluminum Oxide Nanocomposites. Bulletin of Chemical Reaction Engineering \& Catalysis, 15(3), 845-852 (doi:10.9767/bcrec.15.3.8480.845-852)

Permalink/DOI: https://doi.org/10.9767/bcrec.15.3.8480.845-852

\section{Introduction}

In the hydrogenation reactions of unsaturated compounds, homogeneous and heterogeneous

\footnotetext{
* Corresponding Author.

Email: o.ruzimuradov@polito.uz

ruzimuradov@rambler.ru (O. Ruzimuradov);

Tel.: +998 90 9257453; fax: +998 712467082
}

catalysts are mainly used, where transition metal nanoparticles, such as: nickel, platinum, and gold are used as an active element [1-3]. Gold nanoparticles immobilized on metal oxides and platinum group metals: $\mathrm{Pt}, \mathrm{Pd}, \mathrm{Rh}$ stabilized by dendrimers, are used in olefin hydrogenation reactions [4-6]. Despite the high selectivity of hydrogenation, the use of catalysts con- 
taining noble metals increases the cost of the process [7]. Many works indicates that the heterogeneous catalysts are stable and easily separated from the reaction products, but they have low activity and selectivity; reactions in their presence occur at high pressure and temperature. Homogeneous catalysts are difficult to separate from the reaction products and to reuse them. Therefore, it is important to create catalysts with the properties of both homogeneous and heterogeneous, namely with high activity, selectivity, and stability [8].

The catalytic activity and selectivity of catalysts containing nanoparticles depend on their size, texture, structural properties, and electronic state of atoms $[9,10]$. During the hydrogenation of substituted double bonds of unsaturated alcohols, a strong dependence of selectivity on the size of nanoparticles has been found out [11]. The higher the particle size is the higher the selectivity of hydrogenation of disubstituted unsaturated bonds compared to monosubstituted ones, and, conversely, monosubstituted double bonds are more easily hydrogenated at the smallest particle sizes. In most cases, catalytic activity increases when particle size decreases. However, manifestations of the inverse size effect also exist when catalytic activity decreases with the reduction of particle size. For instance, the study [12] presents that the activity of nickel oxide catalysts in the oxidation of carbon dioxide $\left(\mathrm{CO}_{2}\right)$ increases with the rise of specific surface. At the same time, the best catalytic activity is exhibited by the largest nickel oxide nanoparticles in the propane oxidation reaction. Finally, there are some examples of the maximum increase of catalytic activity in a certain particle size [13].

The main disadvantage of the catalysts based on nickel nanoparticles is the rapid deactivation of the catalyst due to various factors, for example, coke deposits. To prevent agglomeration and sintering, the active phase is applied to various inorganic substrates $-\mathrm{Al}_{2} \mathrm{O}_{3}$, $\mathrm{SiO}_{2}$, and $\mathrm{CaCO}_{3}$ [14]. The use of films, for example, $\mathrm{Al}_{2} \mathrm{O}_{3}$ as a matrix, allows combining the flexibility of the electrochemical method for obtaining catalysts and stabilizing nanoparticles in the inert matrix of porous aluminum oxide.

Most activity on the porous aluminum oxide was carried out on rather thick layers of aluminum. The formation of porous anodic oxides on thin Al films (thin plates or foil) has been much less studied, but the thin-film structures with porous aluminum oxide are of great interest for microelectronics, sensor and catalytic devices.
Catalysts on substrates have several advantages, but they have low thermal conductivity. In this regard, it is relevant to create and study of nickel catalysts on metal substrates, to identify patterns of influence of synthesis conditions on the surface structure and to establish the relationship among synthesis conditions, surface structure, and such catalytic properties as an activity, stability of activity and resistance to carbonization of catalysts in the hydrogenation of olefins. Also, it is very important to have a developed surface for all metal catalysts, i.e. to search the ways to increase their specific surface area.

Indeed, the establishment of their structure and nature of interaction with reagent molecules provides valuable information on the mechanisms of catalytic processes. It is the substrate that largely determines the size, shape, and the electronic state of the deposited particle [15-17].

There is very little information about the studies of the hydrogenation of unsaturated hydrocarbons with nanosized metal particles: nickel, cobalt, molybdenum, manganese, chromium and copper. Therefore, the purpose of this article is to obtain nanosized nickel, cobalt and molybdenum catalysts deposited in porous aluminum oxide and to study their activity in olefin hydrogenation reactions as compared to nickel impregnated kieselguhr catalysts. For the first time, as a catalyst we have used the nickel nanoparticles stabilized on the surface of a substrate of porous aluminum oxide (PAO). Aluminum oxide films as the substrates of nanoparticles have several advantages than other substrates (zeolites, silica gel, activated carbon): the ability to stabilize nanoparticles due to charged functional groups and porosity; commercial availability; satisfactory chemical, mechanical and thermal resistance; convenience for transportation and regeneration.

In this paper, porous structures of aluminum oxide have been obtained by anodic oxidation. $\mathrm{Ni} / \mathrm{Al}_{2} \mathrm{O}_{3}$ and $\mathrm{Co}-\mathrm{Mo} / \mathrm{Al}_{2} \mathrm{O}_{3}$ catalysts was prepared by impregnation into nanosized pores of aluminum oxide with pore sizes of $50 \mathrm{~nm}$ and a thickness of $50 \mu \mathrm{m}$. The activity of nickel nanoparticles and heterogeneous cobalt and molybdenum nanoparticles in the reaction of hydrogenation of hexene to hexane have been studied at various temperatures.

\section{Materials and Methods}

We used aluminum films (99.8\%) from Sigma-Aldrich to prepare the porous aluminum oxide. $\mathrm{Ni}\left(\mathrm{NO}_{3}\right)_{2}, \mathrm{Co}\left(\mathrm{NO}_{3}\right)_{2}$ and $\mathrm{Mo}\left(\mathrm{NO}_{3}\right)_{2}$ rea- 
gents, oxalic and orthophosphoric acids used in the experiments, were purchased from Reachim Company (Russia).

The steps for obtaining porous aluminum oxide with an ordered pore structure include annealing, polishing, primary anodizing, removal of the first oxide layer, secondary anodizing, broadening of the pores, fabrication of the membrane: removal of $\mathrm{Al}$ and dissolution of the barrier layer. The advantages of PAO for practical applications are the simplicity and cheapness of its obtaining, the possibility of formation of homogeneous pores in a wide range of sizes - from one to hundreds of nanometers, the ability to control pore sizes by managing the anodic oxidation conditions. Besides, PAO has several unique chemical, mechanical, electrical, and optical characteristics that are important for catalytic applications, including high hardness, thermal stability, and chemical stability in the various environments.

The structure of PAO is described as follows: pore size, simple cell size, barrier layer thickness, and pore length. Depending on the conditions for the formation of PAO, pore sizes can vary from one to hundreds nanometers and the thickness of the porous layer can range from ten nanometers to ten microns. Aluminum plates with a thickness of $50 \mu \mathrm{m}$ are used as a

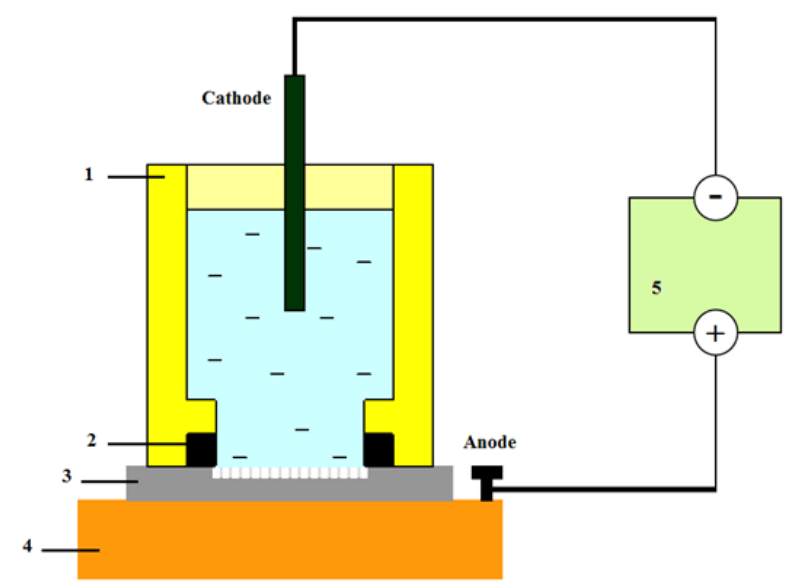

Figure 1. Diagram of a two-electrode electrochemical cell used for anodic oxidation of aluminum: (1) Teflon glass; (2) rubber seal; (3) sample (Al plate); (4) brass base; (5) voltage source. starting material. To increase the size of aluminum crystallites, relieve microstresses, and subsequently achieve better ordering of $\mathrm{Al}$ pores, the substrates are annealed in the air for 10 hours at $550{ }^{\circ} \mathrm{C}$ in a muffle furnace. The surface of the aluminum is leveled with sandpaper.

Anodizing of Al-plates is carried out in a two-electrode chemical cell which is a Teflon glass with $4 \mathrm{~cm}$ opening in diameter in this area and mounted on a brass stand (Figure 1). Samples (Al-plate) are located on a brass stand which is served as the current lead of the anode simultaneously with the function of the mechanical clamp. Using an annular rubber seal and metal mounts, $\mathrm{Al}$-anode is clamped between the brass current lead and the teflon glass which is the body of the electrochemical cell. A carbon rod is used as a cathode. Device B 5-31 is used as a voltage source and it allows conducting the anodization process in a potentiostatic mode. The conditions of anodic oxidation depending on the selected electrolyte is given in Table 1.

It should be noted that a barrier layer is the problem while films of porous aluminum oxide are used as the matrices for the electrochemical production of filamentary nanoparticles. This barrier layer is an insulator and it prevents the nucleation and further growth of metal particles inside the pores. Chemical etching is used, as a rule, in solutions based on orthophosphoric acid to expand the PAO pores and etch the barrier layer, as well as to etch the "sacrificial" layer during two-stage anodizing [20]. After anodization, the first porous layer is etched to the aluminum surface by etching the film at $5 \mathrm{vol} \%$ solution of $\mathrm{H}_{3} \mathrm{PO}_{4}$ at 60 ${ }^{\circ} \mathrm{C}$ for 10 minutes and then the second anodization is carried out. It should be noted that there is a slight increase in pore diameter over their entire depth along with the dissolution of the barrier layer in acid. Depending on the duration of pore etching, it is possible to obtain films of porous aluminum oxide with different pore diameters.

During the anodization, the electrolyte solution is thoroughly mixed at a temperature of 5 ${ }^{\circ} \mathrm{C}$. As a result, $\mathrm{Al}$ substrates with ordered surface roughness are obtained and undertaken

Table 1. The conditions of anodic oxidation of aluminum.

\begin{tabular}{cccc}
\hline Oxidation steps & Electrolyte & $\begin{array}{c}\text { Anodizing voltage and } \\
\text { current, B; A }\end{array}$ & $\begin{array}{c}\text { The duration of oxidation, } \\
\text { hours }\end{array}$ \\
\hline The first oxidation & $0.3 \mathrm{M}(\mathrm{COOH})_{2}$ & $40 ; 2$ & 2 \\
The second oxidation & $0.3 \mathrm{M}(\mathrm{COOH})_{2}$ & $40 ; 2$ & 4 \\
\hline
\end{tabular}


the repeated anodic oxidation under the same conditions. The duration of the second oxidation cycle determines the thickness of the oxide film. The film growth rate under the above anodizing conditions is nearly $2 \mu \mathrm{m} / \mathrm{h}$ with oxalic acid.

During the anodization, the pore diameter of aluminum oxide is determined only by the electrolyte use and the anodizing voltage, and it depends very weakly on the oxidation time. This is due to the low dissolution rate of the oxide in acid. Self-ordering of pores occurs during the prolonged anodic oxidation, where the driving force is the mechanical stress caused by repulsive forces among the adjacent pores.

The formation of PAO is carried out in a two-electrode electrochemical cell with temperature stabilization and mixing electrolyte. Traditional electrolytes for the formation of PAO with a regular porous structure are aqueous solutions of dibasic and tribasic acids (sulfuric, oxalic, malonic, phosphoric, etc.) [18-20]. PAO formation is carried out in a direct current and a voltage mode with oxalic acid (Table 1).

Morphological studies of the obtained catalysts are carried out on a scanning electron microscope of CARL ZEISS (Germany). Electron micrographs are processed with SIAMS600 computer image analysis program. Here we used standard samples made in the form of flat polished disks (diameter $13 \mathrm{~mm}$, thickness 4.5 $\mathrm{mm}$ ) containing Ni. Their spectra were measured on a "Spectroscan Max-G" high-aperture sequential RF spectrometer with wave dispersion ("Spektron", Russia). We used a hydrogen generator from the "Chromatek" Company to obtain hydrogen. The reaction kinetics was studied by gas chromatography on GC with an HP-5MS column using a library of reference mass spectra with data from the computer software for natural compounds "NIST" (National Institute of Standardization \& Technology (NIST) data for GC - MS systems).

\section{Results and Discussion}

3.1 Preparation of Nanostructured Nickel Catalysts Based on a Porous Aluminum Oxide

The study of the process of anodic oxidation of aluminum showed that an ordered pore structure is formed only under certain conditions. For example, aluminum oxide with a distance between pores equal to $50,65,100,420$, and $500 \mathrm{~nm}$ is formed at a voltage of 19 and 25 Volts (V) in sulfuric acid, at $40 \mathrm{~V}$ in oxalic acid, at 160 and $195 \mathrm{~V}$ in phosphoric acid [21-25].

The synthesis of nickel, cobalt and molybdenum nanoparticles into a matrix is carried out by the method of periodic dipping with sequential drying. Precipitation is possible due to the molecular structure of porous $\mathrm{Al}_{2} \mathrm{O}_{3}$. A matrix of porous aluminum oxide with pore sizes of $50 \mathrm{~nm}$ and a thickness of $50 \mu \mathrm{m}$ is used to obtain nickel oxide nanocatalysts based on nickel, cobalt and molybdenum. Figure 2 represents a schematic image of a membrane ready for impregnation of nanoparticles into pores.

The aluminum oxide porous plate is alternately dipped in aqueous solutions of $\mathrm{Ni}\left(\mathrm{NO}_{3}\right)_{2}$ and $\mathrm{Co}\left(\mathrm{NO}_{3}\right)_{2}$ at room temperature, then it is washed in water, dried and again immersed in the solution. After a certain number of impregnation cycles, the plate is annealed within 5 hours in the air at $550{ }^{\circ} \mathrm{C}$. Figure 3 shows the

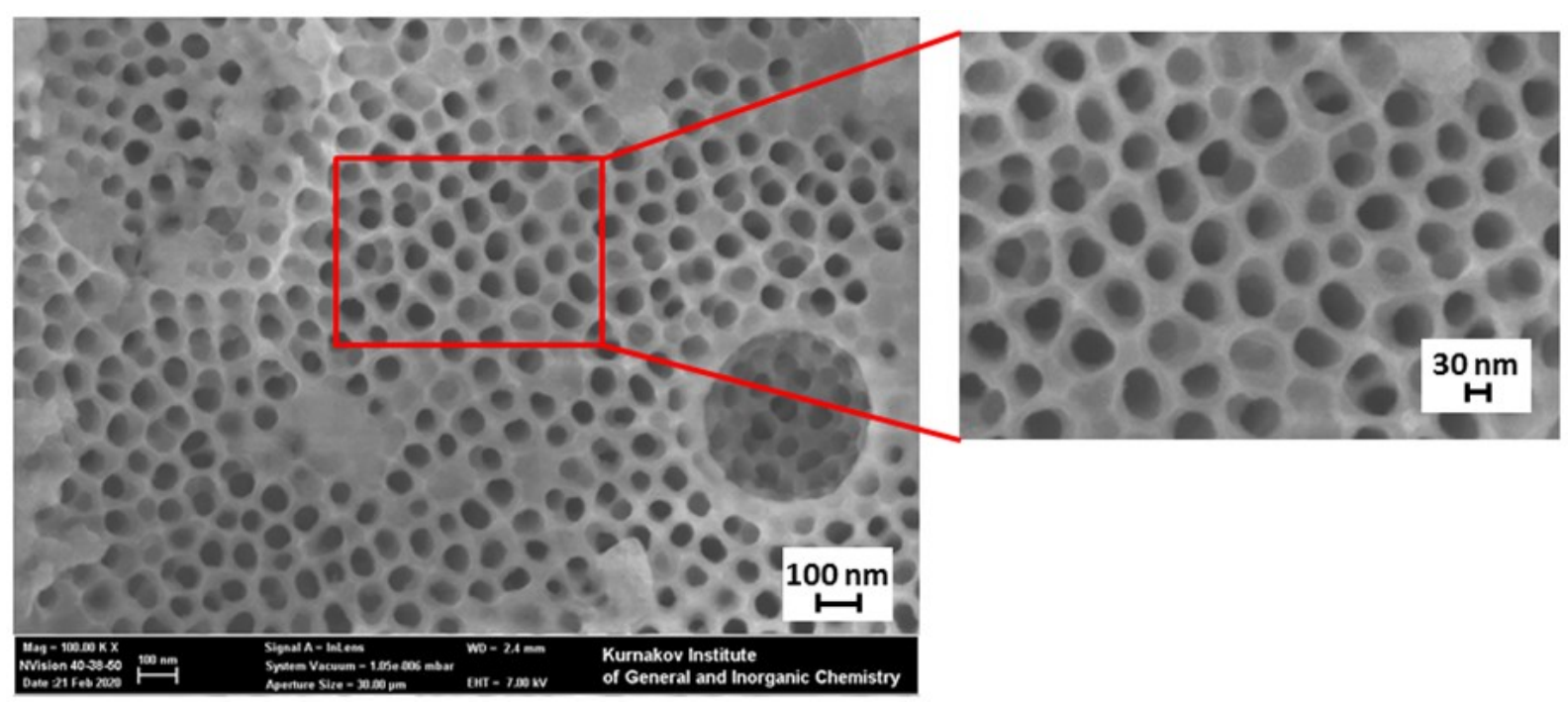

Figure 2. SEM images of PAO nanostructures synthesized by anodic oxidation. The right corner of the figure shows a 3 -fold enlarged portion of the membrane. 
image of the surface of the plate obtained using a scanning electron microscope. The figure shows a mesh structure with filament sizes of 100 nanometers in clusters from 1 to $1.5 \mathrm{mi}$ crons formed on the surface of the plate. By the method of X-ray fluorescence analysis inhomogeneity of quantitative elemental composition
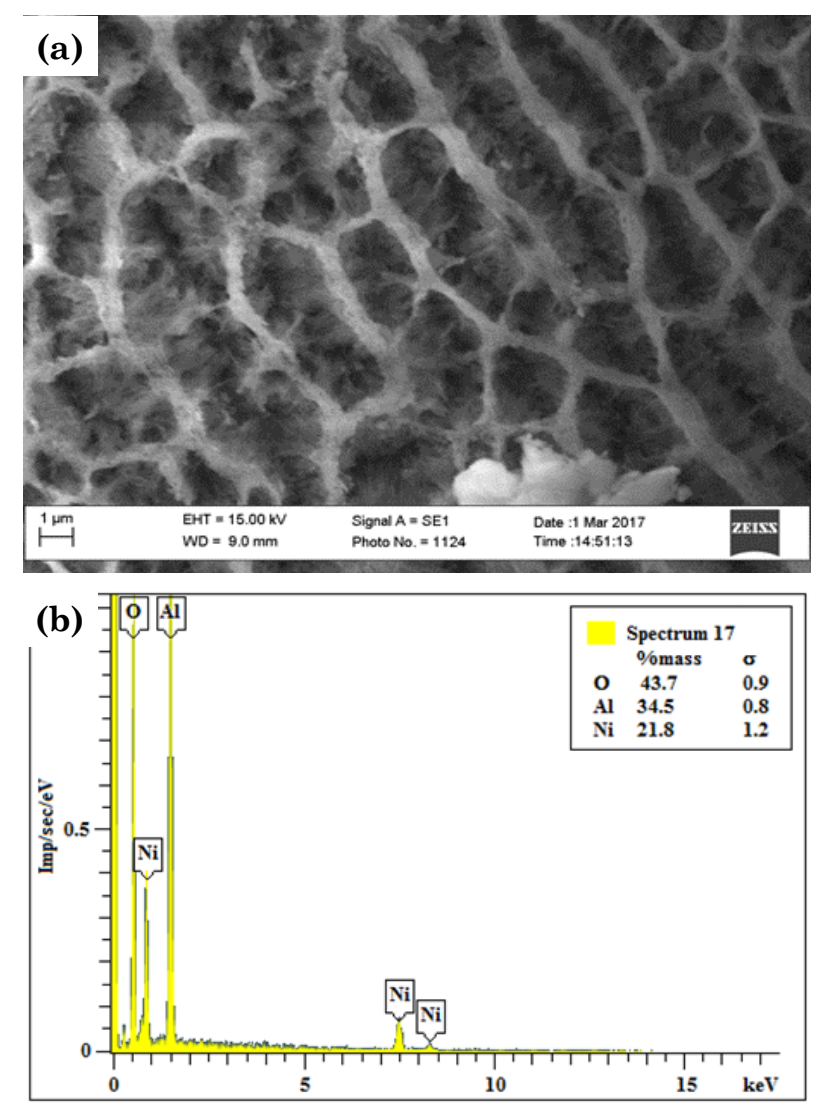

Figure 3. (a) Micrographs of Ni nanostructure on $\mathrm{Al}_{2} \mathrm{O}_{3}$ substrate synthesized by molecular layering. (b) Elemental analysis of the content of substances in the sample: aluminum $34.5 \%$, oxygen $-43.7 \%$ and nickel $-21 \%$.

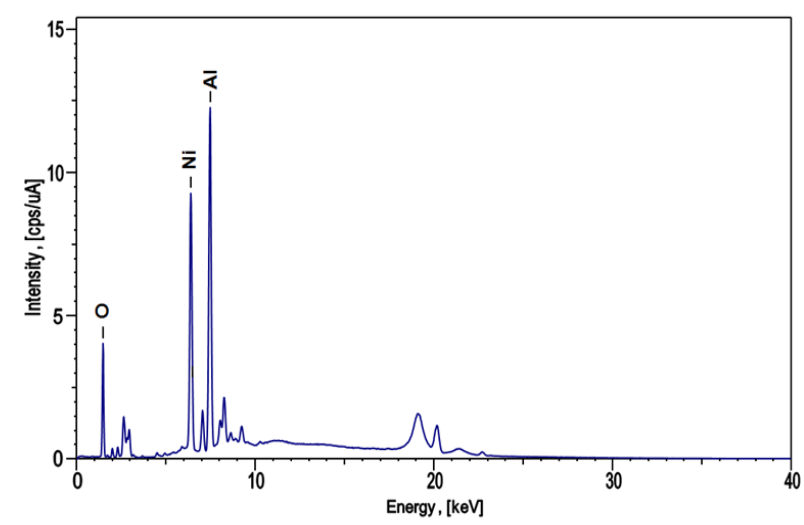

Figure 4. X-ray fluorescence analysis of the elemental composition of $\mathrm{Ni}$ on an $\mathrm{Al}_{2} \mathrm{O}_{3}$ substrate. in the core and the surface layer of the porous $\mathrm{Al}_{2} \mathrm{O}_{3}$ samples of the nickel containing plate has been shown. It was found that the surface layer of the $\mathrm{Ni} / \mathrm{Al}_{2} \mathrm{O}_{3}$ is enriched with nickel (Figure 4). The presence of nickel oxide is also detected in the pores of the anodized aluminum matrix that brings to a mesh morphology of nickel surface on the aluminum oxide surface.

Figure 5 shows images of the surface of the film of $\mathrm{Co}-\mathrm{Mo} / \mathrm{Al}_{2} \mathrm{O}_{3}$ on a scanning electron microscope. This figure represents the formation of a spongy structure with filament sizes within few nanometers on the surface of the plate. Elemental analysis shows that this structure contains molybdenum and cobalt nanoparticles of $14.8 \%$ and $3.4 \%$, respectively. One can see that $\mathrm{Co}-\mathrm{Mo} / \mathrm{Al}_{2} \mathrm{O}_{3}$ has a pure metallic phase and a more uniform morphology than $\mathrm{Ni} / \mathrm{Al}_{2} \mathrm{O}_{3}$. One can see that $\mathrm{Co}-\mathrm{Mo} / \mathrm{Al}_{2} \mathrm{O}_{3}$ has a pure metallic phase and a more uniform morphology than $\mathrm{Ni} / \mathrm{Al}_{2} \mathrm{O}_{3}$.
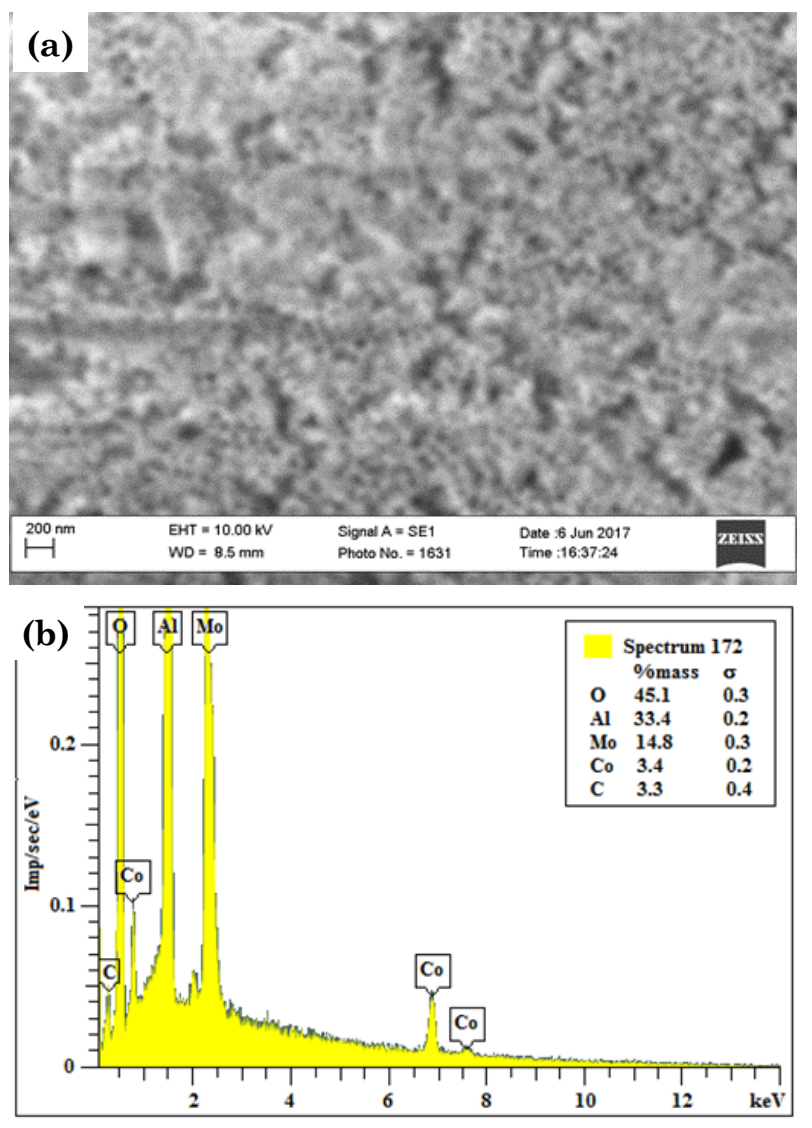

Figure 5. (a) Micrograph of a Co+Mo film on a substrate of porous aluminum oxide and (b) elemental analysis of a catalyst based on $\mathrm{Co}+\mathrm{Mo}$ and $\mathrm{Al}_{2} \mathrm{O}_{3}$. The content of molybdenum and cobalt is $14.8 \%$ and $3.4 \%$, respectively. 


\subsection{Catalytic Activity of Nickel Nanoparticles} in the Hydrogenation of Unsaturated Hydrocarbons

The process of hydrogenation of unsaturated hydrocarbons is one of the main processes of petrochemicals. When fractionating crude oil, unsaturated hydrocarbons are practically inseparable from alkanes having the same mass, and it is necessary to completely eliminate unsaturated hydrocarbons from their composition to obtain the highest quality gasoline. In addition, in petrochemistry the task is to eliminate acetylene hydrocarbons from olefin raw materials intended for the production of polymers [26-28]. The solutions to these two problems require catalysts of different selectivity.

In the present work, the experiments are carried out to study the catalytic activity of nanoparticles in the hydrogenation of olefins. Nanoparticles obtained by impregnation of nickel and cobalt-molybdenum on the surface and into the pores of aluminum oxide are tested in the processing of unsaturated hydrocarbons, i.e. in the conversion of hexene to hexane. Nickel nanoparticles are deposited on an inert $\mathrm{Al}_{2} \mathrm{O}_{3}$ substrate in an amount of $21 \%$ of the mass. The obtained catalyst is loaded into a flow-type reactor in a wet form and dried from water in a stream of hydrogen at a temperature of $120^{\circ} \mathrm{C}$ within 30 minutes. In the reactor, a catalyst layer (small foil pieces) is placed between the inert packing layers (silica glass). After drying,

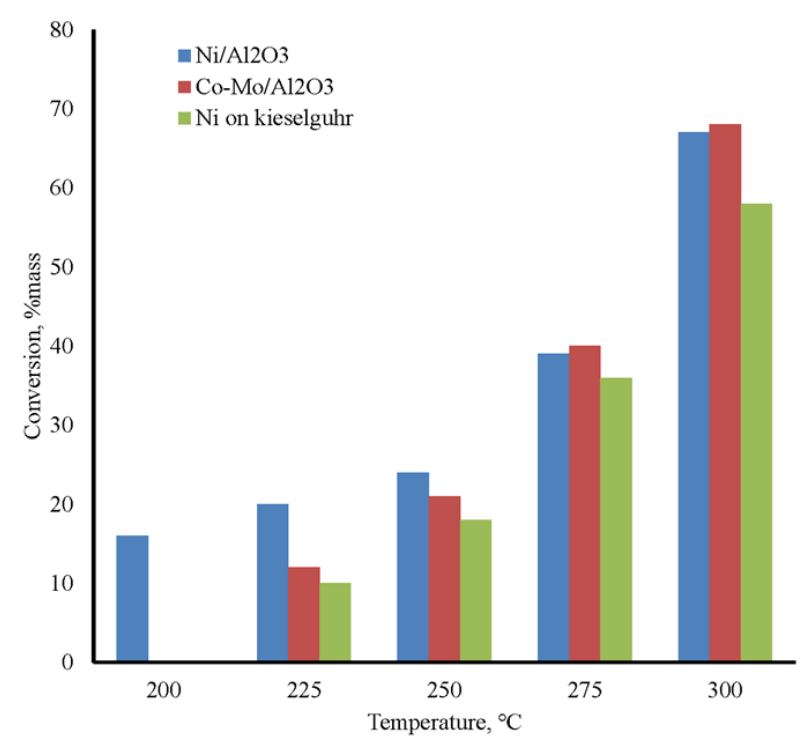

Figure 6. The temperature dependence of the activity of catalysts during the conversion of hexene to hexane: (1) $\mathrm{Ni} / \mathrm{Al}_{2} \mathrm{O}_{3}$ catalyst (the blue column); (2) $\mathrm{Co}-\mathrm{Mo} / \mathrm{Al}_{2} \mathrm{O}_{3}$ catalyst (the red one); (3) traditional nickel catalyst on kieselguhr (the green one). the unsaturated compound and hydrogen are directly dosed to the catalyst at appropriate temperatures from top to bottom. Hydrogenation is carried out for 1 hour at temperatures of $200,230,250,280$, and $300{ }^{\circ} \mathrm{C}$ at a pressure of $30 \mathrm{~atm}$.

Reaction of hexene to hexane conversion can be observed as follows:

$$
\begin{aligned}
\mathrm{CH}_{2} & =\mathrm{CH}-\mathrm{CH}_{2}-\mathrm{CH}_{2}-\mathrm{CH}_{2}-\mathrm{CH}_{3}+\mathrm{H}_{2} \\
& \rightarrow \mathrm{CH}_{3}-\mathrm{CH}_{2}-\mathrm{CH}_{2}-\mathrm{CH}_{2}-\mathrm{CH}_{2}-\mathrm{CH}_{3}
\end{aligned}
$$

with thermal formation $d H_{298 \mathrm{~K}}=2600 \mathrm{~kJ} / \mathrm{mol}$. The conversion of $X_{A}$ is calculated by the following formula:

$$
X_{A}=\frac{C_{A O}-C_{A}}{C_{A O}+\varepsilon C_{A}} 100 \%
$$

where $C_{A}$, and $C_{A}$ are the concentration of the reagents and the yield of hexene and hexane, respectively, and $\varepsilon$ is defined as:

$$
\varepsilon=\frac{E_{p}-E_{r}}{E_{r}}
$$

where $E_{p}$ and $E_{r}$ are the number of moles and reagents respectively. The concentrations of hexene and hexane are determined on an HP$5 \mathrm{MS}$ gas chromatograph.

Figure 6 shows the activity of nickel catalysts impregnated in $\mathrm{Al}_{2} \mathrm{O}_{3}$ nanopores during the conversion of hexene to hexane in comparison with nickel-cobalt and standard nickel catalysts on kieselguhr. One can see that $\mathrm{Ni} / \mathrm{Al}_{2} \mathrm{O}_{3}$ nickel catalyst represents higher activity in hexane conversion and yield of hexane is $15 \%$ at $200{ }^{\circ} \mathrm{C}$. A similar conversion of hexene to hexane with cobalt-molybdenum $/ \mathrm{Al}_{2} \mathrm{O}_{3}$ and traditional nickel catalysts on kieselguhr is achieved at temperatures higher than $250{ }^{\circ} \mathrm{C}$. Probably, cobalt particles block micropores in the $\mathrm{Co}-\mathrm{Mo} / \mathrm{Al}_{2} \mathrm{O}_{3}$ sample, which led to a lower specific area than in the $\mathrm{Ni} / \mathrm{Al}_{2} \mathrm{O}_{3}$ sample, and therefore this factor led to a weak activity of the $\mathrm{Co}-\mathrm{Mo} / \mathrm{Al}_{2} \mathrm{O}_{3}$ sample at low temperatures.

However, the degree of hexane conversion is almost the same for all catalysts and increases up to $70 \%$ at a temperature of $300{ }^{\circ} \mathrm{C}$. The obtained catalysts were stable for 10 hours. SEM analysis (in Figure 3) provided information on the composition of the surface layer of filaments covered with a highly dispersed surface film (clusters) of $\mathrm{NiO}_{1+\mathrm{x}}$ chemically bonded to the surface of the $\mathrm{Al}_{2} \mathrm{O}_{3}$ forming filaments, as well as nickel oxide localized in the pores formed by these alumina filaments. The sample has a gray color, and therefore, most likely, nickel-aluminum spinel, if formed, is in an insignificant amount, which explains the high 
catalytic activity of the sample with supported nickel. Spinel is characterized by a blue color. It has long been known that when heated in hydrogen, a highly dispersed surface film of $\mathrm{NiO}_{1+\mathrm{x}}$ is rather easily reduced to highly dispersed $\mathrm{NiO}$, which is active in hydrogenation and does not sinter at low temperatures under the conditions of a hydrogenation reaction. Of these three nickel structures, nickel oxide in pores is usually reduced at a minimum temperature of up to $300{ }^{\circ} \mathrm{C}$, which is practically not associated with the aluminum oxide substrate. Clusters $\mathrm{NiO}_{1+\mathrm{x}}$ chemically bonded to aluminum oxide by $\mathrm{Ni}-\mathrm{O}-\mathrm{Al}$ bonds are reduced at higher temperatures up to $480{ }^{\circ} \mathrm{C}$, and spinel structures at about $700{ }^{\circ} \mathrm{C}$ and higher.

\section{Conclusion}

Nanosized catalysts $\mathrm{Ni} / \mathrm{Al}_{2} \mathrm{O}_{3}$ and Co$\mathrm{Mo} / \mathrm{Al}_{2} \mathrm{O}_{3}$ using a porous aluminum oxide matrix with pore sizes of about $50 \mathrm{~nm}$ and a thickness of $50 \mu \mathrm{m}$, are obtained by the method of anodic oxidation and impregnation. Porous aluminum oxide is obtained by anodizing at constant voltage and current in a $0.3 \mathrm{M}$ aqueous solution of oxalic acid.

The elemental composition of catalysts containing nickel, cobalt and molybdenum metal particles impregnated into anodized aluminum oxide is determined with a scanning electron microscope and X-ray fluorescence method. The elemental analysis has showed that a spongy structure with filament sizes of few nanometers is formed on the surface of the aluminum oxide matrix, and this structure contains nanoparticles of nickel, cobalt, and molybdenum. The $\mathrm{Ni}$, Co and Mo metals on aluminum oxide are characterized as nanoparticles $(100 \mathrm{~nm})$ in clusters ranging from 1 to $1.5 \mu \mathrm{m}$, and $\mathrm{Ni}$ has a lower average crystallite size than Co and Mo during photomicrographs analysis. $\mathrm{NiO}$ particles are identified in the $\mathrm{Ni} / \mathrm{Al}_{2} \mathrm{O}_{3}$ sample, which influenced the morphology. The $\mathrm{Co}-\mathrm{Mo} / \mathrm{Al}_{2} \mathrm{O}_{3}$ sample has only a pure metallic phase and a more uniform morphology than the nickel sample.

The reaction has shown that during conversion of hexene to hexane, $\mathrm{Ni} / \mathrm{Al}_{2} \mathrm{O}_{3}$ catalyst is active at $200{ }^{\circ} \mathrm{C}$, but $\mathrm{Co}-\mathrm{Mo} / \mathrm{Al}_{2} \mathrm{O}_{3}$ and nickel catalysts on kieselguhr begin to be activated at temperature of about $230^{\circ} \mathrm{C}$, and an equivalent degree of hexane conversion is achieved at temperature of $250{ }^{\circ} \mathrm{C}$. Thus, the studies carried out have shown that $\mathrm{Ni} / \mathrm{Al}_{2} \mathrm{O}_{3}$ catalysts are active in the reactions of hydrocarbon conversion and can be used as catalysts for various oil refining processes. The results of this work are of practical interest in the field of catalysts crea- tion for cracking, isomerization, and aromatization of n-paraffins.

\section{Acknowledgements}

Authors express their gratitude to Mr. Gennady Kopitsa (Researcher of Institute of Silicate Chemistry of Russian Academy of Sciences) for supporting with the morphological analysis. We also thank Dr. Azamjon Soliev for assistance with HP-5MS gas chromatograph measurements. This research is financially supported by Ministry of Innovative Development of the Republic of Uzbekistan (Project \#PZ-20170926279).

\section{Conflicts of interest/Competing interests}

The authors declare that they have no known competing financial interests or personal relationships that could have appeared to influence the work reported in this paper.

\section{References}

[1] Adiga, S.P., Jin, C., Curtiss, L.A., MonteiroRiviere, N.A., Narayan, R.J. (2009). Nanoporous membranes for medical and biological applications. Wiley Interdiscip. Rev. Nanomed. Nanobiotechnol., 1(5), 568-581. DOI: 10.1002/wnan.50.

[2] Majd, S., Yusko, E.C., Billeh, Y.N., Macrae, M.X., Yang, J., Mayer, M. (2010). Applications of biological pores in nanomedicine, sensing, and nanoelectronics. Current Opin. Biotechnol., 21(4), 439-476. DOI: 10.1016/j.copbio.2010.05.002.

[3] Stroeve, P., Ileri, N. (2011). Biotechnical and other applications of nanoporous membranes. Trends Biotechnol., 29(6), 259-266. DOI: 10.1016/j.tibtech.2011.02.002.

[4] Smirnov, V.V., Nikolaev, S.A., Tyurina, L.A., Vasil'kov, A.Yu. (2006). Catalysis of olefin hydrogenation and allylic isomerization by immobilized gold nanoclusters. Petroleum Chemistry, 46, 289-290. DOI: 10.1134/S0965544106040128.

[5] Jin, Z., Xiao, H., Zhou, W., Zhang, D., Peng, X. (2017). Synthesis and hydrogenation application of $\mathrm{Pt}-\mathrm{Pd}$ bimetallic nanocatalysts stabilized by macrocycle-modified dendrimer. Royal Society Open Science, 4(12), 171414. DOI: $10.1098 /$ rsos. 171414.

[6] Hudson, R., Rivière, A., Cirtiua, C.M., Luskaa, K.L., Moores, A. (2012). Iron-iron oxide core-shell nanoparticles are active and magnetically recyclable olefin and alkyne hydrogenation catalysts in protic and aqueous media. Chemical Communications, 48, 33603362. DOI: 10.1039/C2CC16438H. 
[7] Wyrwa, D.W., Schmid, G. (2007). Metal Nanoparticles on stainless steel surfaces as novel heterogeneous catalysts. Journal of Cluster Science, 18(3), 476-493. DOI: 10.1007/s10876007-0123-z.

[8] Bhattacharjee, S., Dotzauer, D.M., Bruening, M.L. (2009). Selectivity as a Function of nanoparticle size in the catalytic hydrogenation of unsaturated alcohols. Journal of the American Chemical Society, 131(10), 3601-3610. DOI: $10.1021 /$ ja807415k.

[9] Popov, Yu.V., Mokhov, V.M., Latyshova, S.E., Nebykov, D.N., Panov, A.O., Davydova, T.M. (2018). Colloidal and nanosized catalysts in organic synthesis: XX. Continuous Hydrogenation of imines and enamines catalyzed by nickel nanoparticles. Russian Journal of General Chemistry, 88, 2035-2038. DOI: $10.1134 / \mathrm{S} 1070363218100018$.

[10] Cölfen, H., Mann, S. (2003). Higher-order organization by mesoscale self-assembly and transformation of hybrid nanostructures. $A n$ gewandte Chemie International Edition, $42(21), \quad 2350-2365$. D O I : 10.1002/anie.200200562.

[11] Keller, F., Hunter, M.S., Robinson, D.L. (1953). Structural features of oxide coatings on aluminum. Journal of the Electrochemical Society, 100(9), 411-419. DOI: 10.1149/1.2781142.

[12] O'Sullivan, J.P., Wood, G.C. (1970). The Morphology and mechanism of formation of porous anodic films on aluminium, Proceedings of the Royal Society of London A - Mathematical and Physical Sciences, 317, 511-543. DOI: 10.1098/rspa.1970.0129.

[13] Morozov, Y.G., Belousova, O.V., Kuznetsov, M.V. (2011). Preparation of nickel nanoparticles for catalytic applications. Inorganic Materials. $\quad 47(1), \quad 36-40$. D O I : $10.1134 / \mathrm{S} 0020168510121027$.

[14] Gene, M.J., Miller, A.V. (1983). Levitation-jet method of producing ultrafine metal powders. Surface. Physics, Chemistry, Mechanics, 2, 150-154.

[15] Kondrat'eva, T.A., Morozov, Yu.G., Chernov, E.A. (1987) Effect of conditions of manufacture on the properties of ultrafine nickel powder. Powder Metallurgy and Metal Ceramics, 26(10), 793-795. DOI: 10.1007/BF00794359.

[16] Gusev, A.I. (2007). Nanomaterials, nanostructures, nanotechnologies. Fizmatlit. Moscow.

[17] Lee, W., Nielsch, K., Gösele, U. (2007). Selfordering behavior of nanoporous anodic aluminum oxide (AAO) in malonic acid anodization. Nanotechnology, 18, 475713.
[18] Chu, S.Z., Wada, K., Inoue, S., Isogai, M., Katsuta, Y., Yasumori, A. (2006). Large-Scale fabrication of ordered nanoporous alumina films with arbitrary pore intervals by criticalpotential anodization. J. Electrochem. Soc., 153, B384. DOI: 10.1149/1.2218822.

[19] Ryu, Y.R., Lee, T.S., White H.W. (2003). Properties of arsenic-doped p-type $\mathrm{ZnO}$ grown by hybrid beam deposition. Appl. Phys. Lett., 83(1), 87-89. DOI: 10.1063/1.1590423.

[20] Garces, N.Y., Giles, N.C., Halliburton, L.E., Cantwell, G., Eason, D.B., Reynolds, D.C., Look, D.C. (2002). Production of nitrogen acceptors in $\mathrm{ZnO}$ by thermal annealing. Appl. Phys. Lett., 80(8), 1334-1336. DOI: 10.1063/1.1450041.

[21] Shingubara, S. (2003). Fabrication of nanomaterials using porous alumina templates. Journal of Nanoparticle Research, 5, 17-30. DOI: 10.1023/A:1024479827507.

[22] Nielsch, K., Choi, J., Schwirn, K., Wehrspohn, R.B., Gösele, U. (2002). Selfordering regimes of porous alumina: The $10 \%$ porosity rule. Nano Letters, 2(7), 677-680. DOI: $10.1021 / \mathrm{nl} 025537 \mathrm{k}$.

[23] Jessensky, O., Müller, F., Gösele, U. (1998). Self-organized formation of hexagonal pore arrays in anodic alumina. Applied Physics Letters, 72, 1173-1175. DOI: 10.1063/1.121004.

[24] Masuda, H., Yamada, H., Satoh, M., Asoh, H., Nakao, M., Tamamura, T. (1997). Highly ordered nanochannel-array architecture in anodic alumina. Applied Physics Letters, 71, 2770-2772. DOI: 10.1063/1.120128.

[25] Babaev, M.I., Mikhalev, M.S. (2006). Catalyst of catalytic cracking. Oil refining and petrochemistry. in Research and Development Achievements and the Best Practice, 10, 13-15.

[26] Maksimyuk, L.P., Edigarova, V.S., Celidi, E.I. (1990) Prediction of the effectiveness of the application of new cracking catalysts in industrial conditions. Oil Refining and Petrochemistry, 12, 7-10.

[27] Lipin, P.V., Doronin, V.P., Gulyaeva, T.I. (2010). Conversion of higher n-alkanes under deep catalytic cracking conditions. Petroleum Chemistry, 50(2), 362-367. DOI: 10.1134/S0965544110050075.

[28] Abramova, A.V., Slivinskii, E.V., Goldfarb, Yu.Ya., Panin, A.A., Kulikova, E.A., Kliger, G.A. (2005). Development of efficient zeolitecontaining catalysts for petroleum refining and petrochemistry. Kinetics and Catalysis, 46, 758-769 DOI: 10.1007/s10975-005-0133-5 